\title{
EMPLOYMENT AFTER LUNG TRANSPLANTATION IN POLAND - A SINGLE CENTER STUDY
}

\section{MAREK OCHMAN ${ }^{1,2}$, MAGDALENA LATOS ${ }^{1}$, GABRIELA ORZEŁ ${ }^{1}$, PAULINA PAŁKA ${ }^{1}$, MACIEJ URLIK ${ }^{1}$, MIROSŁAW NECCKI ${ }^{1}$, TOMASZ STĄCEL ${ }^{1}$, and MARIAN ZEMBALA ${ }^{1}$}

\author{
Medical University of Silesia in Katowice, Zabrze, Poland \\ ${ }^{1}$ Silesian Center for Heart Diseases, Department of Cardiac, Vascular and Endovascular Surgery and Transplantology \\ ${ }^{2}$ Department of Pharmacology, School of Medicine with the Division of Dentistry in Zabrze
}

\begin{abstract}
Objectives: Lung transplantation not only saves a patient's life but also creates the opportunity for becoming more self-reliant and getting back to work. The aim of this single center study was to assess the prospects of employment, as well as its influence on the quality of life and physical activity, of the lung transplant recipients of the Silesian Center for Heart Diseases in Zabrze, Poland. Material and Methods: A retrospective study covered 67 lung transplant recipients of the Silesian Center of Heart Diseases. Only patients with $\geq 6$-month follow-up were included. All of the patients gave their written consent to be included in the study before filling out the questionnaire containing questions about employment, income, education and how work affected their quality of life before and after lung transplantation. A physical capability assessment was performed by climbing flights of stairs and by means of a 6-min walk test, and spirometry parameters were also measured. Results: Twenty of the patients included in the study (31.7\%) were employed after lung transplantation, $63.2 \%$ of whom worked full-time. Profession was changed by 2 patients (14.3\%). The patients diagnosed with cystic fibrosis were found to have the highest chance of finding employment after lung transplantation. The statistical analysis revealed that the employed patients were able to cover longer distances during the 6-min walk test (556 m, on average) than the unemployed ones (494 m, on average). Conclusions: One in 3 patients finds employment after lung transplantation. Work improves the quality of life of the majority of lung transplant recipients. The patients who are employed are also in a better physical condition, and they are more self-reliant in comparison to those who remain unemployed. Lung transplant recipients with cystic fibrosis are most likely to find employment, and so are patients with higher education. Int J Occup Med Environ Health. 2019;32(3):379-86
\end{abstract}

Key words:

occupational medicine, cystic fibrosis, lung transplantation, solid organ transplantation, employment in Poland, employment after transplantation

\section{INTRODUCTION}

Solid organ transplantation has become a viable treatment for patients with end-stage organ failure all over the world. Such treatment not only saves lives but also provides a chance of improving the patient's condition up to the point of rejoining the workforce. It is, therefore, currently recommended [1,2]. In the case of end-stage kidney failure, transplantation has even proven superior to dialysis in terms of the potential to return to work, as well as in terms of labor income and the risk of early retirement [3]. However, not all the solid organ recipients have the same chances of returning to work. An assessment of whether the type of the transplanted organ matters has revealed that kidney recipients are most likely to find a job, with an employment rate of $58.6 \%$ [1]. Many factors influence the chance of returning to work after solid organ transplantation.

Received: May 26, 2018. Accepted: January 18, 2019.

Corresponding author: Marek Ochman, Medical University of Silesia in Katowice, Silesian Center for Heart Diseases, Department of Cardiac, Vascular and Endovascular Surgery and Transplantology, Skłodowskiej-Curie 9, Pawilon C, 41-800 Zabrze, Poland (e-mail: ochmann@wp.pl). 
Unfortunately, transplantations of organs other than lungs have been associated with a higher chance of getting employment [1]. According to the Polish Organization and Coordination Center for Transplantation (PolTransplant), lung is the least frequently transplanted organ in Poland [4]. Nevertheless, such patients can seek employment like any other graft recipients. The following factors have been found to affect this capability: pre-transplantation employment, a diagnosis of emphysema, cystic fibrosis or primary pulmonary hypertension, a self-report of being physically able to work, a greater functional improvement, as measured by the post-lung transplantation percent predicted forced vital capacity, and the post-lung transplantation 6-min walk test (6MWT) $>550 \mathrm{~m} \mathrm{[5].}$ What is more, preoperative functional independence and the maintenance of employment at the time of transplantation are associated with superior long-term outcomes in lung recipients [6]. It has been demonstrated that the type of lung transplantation (single lung transplantation or double lung transplantation) does not have an effect on employment [5]. The aim of this single center study was to assess the prospects of employment, along with the quality of life and physical activity of the lung transplant recipients treated in the Silesian Center for Heart Diseases (Śląskie Centrum Chorób Serca - SCCS).

\section{MATERIAL AND METHODS}

A retrospective exploratory study covered 67 lung transplant recipients (26 women and 41 men) of the Silesian Center for Heart Diseases in Zabrze, Poland. Only patients with at least 6-month follow-up were included. The average age of the patients was 45 years (min. 23 years, $\max 72$ years). The studied patients represented $91.78 \%$ of the Center's alive patients with the required followup. In Poland, 216 lung transplantations were performed in 1996-2017.

The lung transplant division of the Silesian Center for Heart Diseases performed $73.15 \%$ of these surgeries, which means that this is the largest amount of data available from a single center in Poland. Single lung transplantation was performed in $34.4 \%$ of the patients while $65.7 \%$ became double lung transplant recipients.

Prior to transplantation, the patients were diagnosed with the following diseases: cystic fibrosis (CF) $-22.4 \%$, chronic obstructive pulmonary disease (COPD) $-19.4 \%$, idiopathic pulmonary arterial hypertension (IPAH) $-17.9 \%$, idiopathic pulmonary fibrosis (IPF) $-14.9 \%$, and other interstitial lung diseases (ILD) - 25.4\%, including sarcoidosis (4.6\%), lymphangioleiomyomatosis (LAM) $(3 \%)$ and others. The average time spent on the Polish National Lung Transplant Waiting List was 14.2 months.

The current retirement age in Poland is 60 for women and 65 for men.

The study focused on the analysis of employment, income, education and how work affected the quality of life after lung transplantation. All of the patients gave their written consent to be included in the study before filling out the questionnaire containing questions about employment, income, education and how work affected their quality of life before and after lung transplantation. The study was approved by the local ethics committee. A physical capability assessment was performed by climbing flights of stairs and by means of a 6MWT, and spirometry parameters were measured by the properly trained personnel during the patients' hospital stay.

\section{Statistical analysis}

Differences observed between the employed and unemployed patients were statistically analyzed by means of the Mann-Whitney $U$ test and the $\chi^{2}$ test with Yates correction. A $p$ value $<0.05$ was established as statistically significant.

\section{RESULTS}

As regards the male patients, $100 \%$ of them were transplanted at the age of $<65$ years, which means none was on retirement, and only 4 patients $(9.8 \%)$ were 
$>60$ years old. As regards the female population, $96.2 \%$ were $<60$ years old, and only 1 woman was transplanted while being on retirement.

\section{Assessment of employment before lung transplantation}

The results of a detailed analysis of employment before lung transplantation are presented in Table 1. Mixed income means that the patients had an additional source of income besides working. In Poland, it is legal to be on retirement and to work part-time. The response "Other source of income" mentioned in Table 1 means that this information was not disclosed by the patient. In gener$\mathrm{al}, 76.1 \%$ of the patients had worked at some point before lung transplantation, $10.4 \%$ were students, 1 patient was employed and studied at the same time, and 8 patients $(11.9 \%)$ had never worked.

\section{Assessment of employment after lung transplantation}

Twenty patients (31.7\%) were employed after lung transplantation, with men becoming employees more often than women (75\% vs. $25 \%$ ). The average age of the employed men was 37 years ( $\mathrm{Me}=31$ years), and the average age of the employed women was 31 years ( $\mathrm{Me}=26$ years). The unemployed patients were older than those who had returned to work (41 years among men and 38 years among woman). After lung transplantation, 25.5\% of the patients resumed employment. One patient out of $7 \mathrm{stu}-$ dents became an employee. From the previously unemployed group, 6 patients (75\%) were hired. The student/ employee patient resumed both activities after lung transplantation. The average time of looking for a job after lung transplantation was 16 months.

The employed lung transplant recipients were working $38 \mathrm{~h} /$ week, on average, including $63.2 \%$ of the patients working full-time. Profession was changed by 2 patients $(14.3 \%)$, while 8 patients $(40 \%)$ decided to retrain or gain new skills in order to be employed.

The patients stated that they had many reasons to seek employment after lung transplantation, with the financial factor being the most frequent. The second most common cause was eagerness to engage in social contacts. Problems at work, which were connected with incomplete physical fitness, were reported by 3 patients (17.6\%).

Pulmonary function tests, such as a 6MWT, and spirometry results were also assessed at the time of filling out the questionnaire. Details are presented in Table 2. It was statistically significant that the employed patients were able to walk approximately $60 \mathrm{~m}$ more than the unemployed

Table 1. The source of income 12 months before the lung transplantation (LT) performed in Poland in 1996-2017the study by the Silesian Center for Heart Diseases in Zabrze, Poland

\begin{tabular}{lcccc}
\hline \multirow{2}{*}{ Source of income } & \multicolumn{3}{c}{$\begin{array}{c}\text { Patients } \\
\text { (N = 67) } \\
{[\%]}\end{array}$} & \multirow{2}{c}{$\mathrm{p}$} \\
\cline { 2 - 4 } & total & $\begin{array}{c}\text { employed } \\
\text { after LT }\end{array}$ & $\begin{array}{c}\text { unemployed } \\
\text { after LT }\end{array}$ & \\
\hline Work & 11.9 & 15 & 11.6 & 0.927 \\
Pension & 61.2 & 55 & 62.8 & 0.686 \\
Retirement pension & 1.5 & 0 & 2.3 & 0.657 \\
Mixed income & 19.4 & 20 & 18.6 & 0.797 \\
Parents' support & 4.5 & 10 & 2.3 & 0.435 \\
Other & 1.5 & 0 & 1 & 0.657 \\
\hline
\end{tabular}


Table 2. The 6-min walk test (6MWT) and spirometry results of the patients with the lung transplantation (LT) performed in Poland in 1996-2017 - subjects of the Silesian Center for Heart Diseases in Zabrze, Poland

\begin{tabular}{|c|c|c|c|c|c|}
\hline & \multicolumn{4}{|c|}{$\begin{array}{l}\text { Patients after LT } \\
\quad(\mathrm{N}=67)\end{array}$} & \multirow{3}{*}{$\mathrm{p}^{\mathrm{a}}$} \\
\hline & \multicolumn{2}{|c|}{$\begin{array}{l}\text { employed } \\
(\mathrm{N}=20)\end{array}$} & \multicolumn{2}{|c|}{$\begin{array}{l}\text { unemployed } \\
(\mathrm{N}=47)\end{array}$} & \\
\hline & M & SD & M & $\mathrm{SD}$ & \\
\hline $6 \mathrm{MWT}$ & 556.1 & 108.2 & 494.1 & 118.1 & 0.043 \\
\hline \multicolumn{6}{|c|}{ Forced expiratory volume } \\
\hline in liters $\left(\mathrm{FEV}_{1}[1]\right)$ & 2.28 & 0.76 & 1.98 & 0.86 & 0.131 \\
\hline in $\%\left(\mathrm{FEV}_{1} \%\right)$ & 64.0 & 21.1 & 62.1 & 22.4 & 0.706 \\
\hline \multicolumn{6}{|l|}{ Forced vital capacity } \\
\hline in litres (FVC [1]) & 3.28 & 0.80 & 2.76 & 0.87 & 0.018 \\
\hline in $\%(\mathrm{FVC} \%)$ & 76.8 & 17.3 & 71.5 & 16.1 & 0.244 \\
\hline
\end{tabular}

${ }^{\text {a }}$ Mann-Whitney U test.

Bolded - p value $<0.05$.

Table 3. Employment by underlying lung disease after the lung transplantation (LT) performed in Poland in 1996-2017 - the study by the Silesian Center for Heart Diseases in Zabrze, Poland

\begin{tabular}{|c|c|c|c|}
\hline \multirow[t]{2}{*}{ Underlying lung disease } & \multicolumn{2}{|c|}{$\begin{array}{c}\text { Patients after LT } \\
(\mathrm{N}=67) \\
{[\%]}\end{array}$} & \multirow[t]{2}{*}{$\mathrm{p}$} \\
\hline & $\begin{array}{c}\text { employed } \\
(\mathrm{N}=20)\end{array}$ & $\begin{array}{l}\text { unemployed } \\
(\mathrm{N}=47)\end{array}$ & \\
\hline Chronic obstructive pulmonary disease (COPD) & 15 & 20.9 & 0.797 \\
\hline Idiopathic pulmonary fibrosis (IPF) & 10 & 18.6 & 0.572 \\
\hline Cystic fibrosis (CF) & 40 & 16.3 & 0.053 \\
\hline Idiopathic pulmonary arterial hypertension (IPAH) & 20 & 18.6 & 0.797 \\
\hline Interstitial lung disease (ILD) & 15 & 25.6 & 0.531 \\
\hline
\end{tabular}

ones. The working patients also presented better results of the forces vital capacity in liters in comparison to those without a job.

The marital status of the patients was also analyzed. In the studied population, $40 \%$ of the patients were single and $60 \%$ were in a relationship. In comparison to the working group, single patients were less numerous in the unemployed group (31\%) while patients with partners accounted for $66.7 \%$ of the group.
Detailed results of employment after lung transplantation by underlying lung disease are presented in Table 3 . The patients diagnosed with CF had the highest chance of employment after lung transplantation.

Hospital rehabilitation was performed in $25.4 \%$ of the patients prior to lung transplantation. Hospital rehabilitation after lung transplantation was provided to all the patients $(100 \%)$ and lasted at least 6 weeks. The average rehabilitation time was longer ( 9 weeks) in the case of 
the eventually employed patients in comparison to those eventually unemployed (7 weeks).

\section{Assessment of the influence of work \\ on the quality of life after lung transplantation}

The influence of work on the lung transplant recipients' quality of life was also assessed. Among the employed patients, $72.2 \%$ stated that work improved their life, $16.7 \%$ believed that it had no influence at all, and the remaining $11.1 \%$ expressed an opinion that work activities decreased their quality of life.

\section{Assessment of physical activity after lung transplantation}

After lung transplantation, the majority of patients were able to take up regular physical activities (89.6\%). This percentage was higher among the patients who were employed (95\%). A significant number of the unemployed graft recipients were also able to perform physical exercise $(86 \%)$ regularly. The type of physical activities was also studied. Strength training as the only physical activity was not implemented in the fitness routine of any of the lung transplant recipient, but it was more popular as a part of mixed training with the addition of endurance exercises. As many as $43.3 \%$ of all the lung transplant recipients participated in mixed training $(55 \%$ of the working patients and $34.9 \%$ of the unemployed ones). The most frequent physical activity among the transplanted patients in general was endurance training (53.3\% of patients). This form of activity was chosen by $40 \%$ of the employed patients and $46.5 \%$ of the unemployed group. Physical activity was also measured by the ability to climb flights of stairs. Detailed results of this test are presented in Table 4. It was interesting to see that the employed patients were generally able to climb more flights of stairs than those who were not employed.

Self-reliance is also important in daily life. In the studied group, $85.7 \%$ of the patients did not need help with physical activities while 8 patients claimed that they needed such assistance (12.7\%). One patient also reported using a walker $(1.6 \%)$. The majority of the employed patients were self-reliant (95\%), and only few were in need of assistance $(5 \%)$. The percentage of patients needing assistance was higher in the unemployed study group (16.3\%). Fewer unemployed patients were also self-reliant $(81.4 \%)$.

The patients' educational level, skillset and qualifications also play a role on the labor market. The results of a detailed analysis of this issue are presented in Table 5. The majority of the patients after lung transplantation had secondary education, with $34.38 \%$ of them being employed. However, the highest employment after lung transplantation was observed among the lung transplant recipients

Table 4. An assessment of physical capability measured by the ability to climb flights of stairs among the patients after the lung transplantation (LT) performed in Poland in 1996-2017 - the study by the Silesian Center for Heart Diseases in Zabrze, Poland

\begin{tabular}{|c|c|c|c|c|}
\hline \multirow[t]{2}{*}{ Flights of stairs } & \multicolumn{3}{|c|}{$\begin{array}{l}\text { Patients after LT } \\
(\mathrm{N}=67) \\
{[\%]}\end{array}$} & \multirow[t]{2}{*}{$\mathrm{p}$} \\
\hline & total & $\begin{array}{c}\text { employed } \\
(\mathrm{N}=20)\end{array}$ & $\begin{array}{l}\text { unemployed } \\
(\mathrm{N}=47)\end{array}$ & \\
\hline$<1$ & 10.9 & 5.3 & 12.5 & 0.690 \\
\hline 1 & 20.3 & 5.3 & 25 & 0.144 \\
\hline 2 & 26.6 & 26.6 & 27.5 & 0.828 \\
\hline$\geq 3$ & 42.2 & 63.2 & 37.5 & 0.117 \\
\hline
\end{tabular}


Table 5. Education of the lung transplant recipients after the transplantation performed in Poland in 1996-2017the study by the Silesian Center for Heart Diseases in Zabrze, Poland

\begin{tabular}{lcccc}
\hline \multirow{2}{*}{ Education } & \multicolumn{3}{c}{$\begin{array}{c}\text { Patients } \\
(\mathrm{N}=67) \\
{[\%]}\end{array}$} & p \\
\cline { 2 - 4 } & total & employed & unemployed & 0.244 \\
\hline Higher & 19 & 30 & 48.8 & 0.853 \\
Vocational & 19.8 & 55 & 20.9 & 0.831 \\
Secondary & 51.6 & 15 & 14 & 0.195 \\
Basic & 9.5 & 0 & & \\
\hline
\end{tabular}

with higher education $(50 \%)$ while only $25 \%$ of the patients with vocational education were employed after lung transplantation. None of the patients with basic education found employment after becoming a graft recipient.

\section{DISCUSSION}

Solid organ transplantation gives the patient a chance not only to have his/her life prolonged but also to improve its quality. Resuming or finding employment after becoming a graft recipient is just another measure of successful treatment. A Swiss transplant cohort study presented by Vieux et al. [7] assessed the prospects of employment after the first solid organ transplantation (kidney, liver, heart or lung). The authors estimated that $49.8 \%$ of the studied recipients were employed 12 months after receiving the graft [7]. The highest employment rates after solid organ transplantation could be observed after kidney transplantation (58.6\%) [1].

Even though lung transplant recipients are considered the least likely to be employed, in comparison to other organ recipients [1], they can still find employment. The first research about the employment of lung transplant recipients, conducted by Paris et al. in 1998, reported that $37 \%$ of the medically able patients worked after lung transplantation [5]. Patrice et al. [8] conducted a study assessing, i.e., the prospects of employment after thoracic organ transplantation. His team found out that $>40 \%$ of graft recipients worked after the procedure [8]. In the present study, it was assessed that $31.7 \%$ of lung transplant recipients were employees. Other studies found that this percentage was similar in other countries. Debierne et al. estimated that $28.1 \%$ of lung transplant recipients were employed [1]. Soling et al. stated that in Germany this percentage was higher, with $38 \%$ of employed patients [2]. In some countries, like Australia, employment after lung transplantation was found to reach $44 \%$ among the patients who had not given up work before transplantation, as it was presented by Cumming et al. [9].

Moreover, the employment of lung recipients is also affected by the local unemployment rates [10]. The time of resuming or taking up employment after lung transplantation is also important. Research published by Temin et al. concluded that early return to work might benefit the patients experiencing mild functional limitations, as well as that the best time to resume work, to coincide with the best functional status after lung transplantation, would be 12 months post-transplant [11]. In the present study, the patients either resumed or found a job after approximately 14 months. Cystic fibrosis, primary arterial hypertension and emphysema were associated with higher chances of finding employment, as it was assessed by Paris et al. [5]. It was also confirmed by this study, as the patients diagnosed with cystic fibrosis prior to transplantation were most likely to find employment after the 
procedure (40\%). The authors consider this result to be comparable with other countries, as Krivchenia et al. estimated that 5 -year salaried work was possible for $48 \%$ of the CF patients undergoing transplantation [12].

Pre-transplant employment seems to be one of the most important factors when it comes to returning to work after lung transplantation [5,7]. What is more, it is also an important factor of rejoining the workforce after liver transplantation [13]. Heart recipients also are more likely to work after receiving the graft if they have been previously employed [8]. Moreover, Ravi et al. observed that the patients who had worked prior to heart transplantation presented lower 5-year and 10-year mortality rates after the procedure [14].

Salaried work does not only provide the necessary means for survival but also improves the quality of life. As many as $72.2 \%$ of the lung transplant recipients of the SCCS claimed that being employed improved their quality of life. A similar percentage could be found in the research done by Soling et al. [2]. According to their data, $80 \%$ of the respondents agreed that employment led to a better quality of life. Their work also emphasized the fact that patients with higher education and better physical fitness were more likely to find employment. Among the lung transplant patients of the SCCS, the highest percentage of employed people was observed in the higher education group (50\%).

What is more, a greater percentage of the employed patients were able to take up physical exercise and climb $\geq 3$ flights of stairs. The authors also believe that these factors make patients more self-reliant, and that such patients are more likely to become employed. Better 6MWT and spirometry results were observed among the employed patients, which is consistent with the findings by Paris et al., who proved that the functional improvement measured by the percent predicted forced vital capacity and 6-min walk distance $>550 \mathrm{~m}$ after transplantation was connected with a higher chance of finding a job [5].
This study confirmed that relatively good results of forced vital capacity could possibly be connected with a better chance of employment. However, the statistical analysis of the authors' data established that for the amount measured by liters, and not as a percentage of the predicted value, as was done in the aforementioned study.

Even though the number of the studied patients appears small, it is the largest collection of data regarding this topic in Poland. The small number of patients has its limitations; therefore, every studied aspect was statistically analyzed. Taking up work after solid organ transplantation seems to be a socially and medically important topic, as the goal of this treatment is to provide self-reliance and good-quality life. The authors of this study believe that this topic requires further assessment, as the number of graft recipients, who are also potential workers, will increase over time.

\section{CONCLUSIONS}

One in 3 patients finds employment after lung transplantation. Work improves the quality of life of the majority of lung transplant recipients. The patients who are employed are also in a better physical condition, and they are more self-reliant in comparison to those who are unemployed. This finding is confirmed by the fact that the employed patients get better results of 6MWT and forced vital capacity measured by liters. The lung transplant recipients with cystic fibrosis are most likely to find employment, and so are patients with higher education. The authors are aware of the study's limitations resulting from the small study group.

\section{REFERENCES}

1. De Baere C, Delva D, Kloeck A, Remans K, Vanrenterghem Y, Verleden G, et al. Return to work and social participation: does type of organ transplantation matter? Transplantation. 2010;89(8):1009-15, https://doi.org/10.1097/TP.0b013e 3181ce77e5. 
2. Suhling H, Knuth C, Haverich A, Lingner H, Welte T, Gottlieb J. Employment after lung transplantation - a single-center cross-sectional study. Dtsch Arztebl Int. 2015;112(13):213-9.

3. Jarl J, Gerdtham UG, Desatnik P, Prütz KG. Effects of kidney transplantation on labor market outcomes in Sweden. Transplantation.2018;102(8):1375-81,https://doi.org/10.1097/TP.00 00000000002228 .

4. Malanowski P. Przeszczepianie narządów w Polsce w latach 1966-2017. Poltransplant Biul Inf 2018;26(1):30-1. Polish.

5. Paris W, Diercks M, Bright J, Zamora M, Kesten S, Scavuzzo M, et al. Return to work after lung transplantation. J Heart Lung Transplant. 1998;17(4):430-6.

6. Osho A, Mulvihill M, Lamba N, Hirji S, Yerokun B, Bishawi M, et al. Is functional independence associated with improved long term survival after lung transplantation? Ann Thorac Surg. 2018;106(1):79-84, https://doi.org/10.1016/j.athor acsur.2018.01.069.

7. Vieux L, Simcox AA, Mediouni Z, Wild P, Koller M; and the Swiss Transplant Cohort Study, et al. Predictors of return to work 12 months after solid organ transplantation: Results from the Swiss Transplant Cohort Study. J Occup Rehabil. 2018, https://doi.org/10.1007/s10926-018-9804-8.

8. Petrucci L, Ricotti S, Michelini I, Vitulo P, Oggionni T, Cascina A, et al. Return to work after thoracic organ transplantation in a clinically-stable population. Eur J Heart Fail. 2007;9(11): 1112-9, https://doi.org/10.1016/j.ejheart.2007.08.002.
9. Cumming K, O’Brien L, Harris J. Predictors of employment participation following lung transplant. Aust Occup Ther J. 2016;63(5):347-51, https://doi.org/10.1111/1440-1630. 12315.

10. Nau M, Shrider EA, Tobias JD, Hayes D Jr, Tumin D. High local unemployment rates limit work after lung transplantation. J Heart Lung Transplant. 2016;35(10):1212-9, https:// doi.org/10.1016/j.healun.2016.05.002.

11. Tumin D, Kirkby SE, Tobias JD, Hayes D Jr. Attained functional status moderates survival outcomes of return to work after lung transplantation. Lung. 2016;194(3):437-45, https://doi.org/10.1007/s00408-016-9874-3.

12. Krivchenia K, Hayes D Jr, Tobias JD, Tumin D. Long-term work participation among cystic fibrosis patients undergoing lung transplantation. J Cyst Fibros. 2016;15(6):846-9, https://doi.org/10.1016/j.jcf.2016.07.007.

13. Huda A, Newcomer R, Harrington C, Keeffe EB, Esquivel CO. Employment after liver transplantation: a review. Transplant Proc. 2015;47(2):233-9, https://doi.org/10.1016/ j.transproceed.2014.10.022.

14. Ravi Y, Lella SK, Copeland LA, Zolfaghari K, Grady K, Emani S. Does recipient work status pre-transplant affect post-heart transplant survival? A United Network for Organ Sharing database review. J Heart Lung Transplant. 2018;37(5):604-10, https://doi.org/10.1016/j.healun. 2018.01.1307.

This work is available in Open Access model and licensed under a Creative Commons Attribution-NonCommercial 3.0 Poland License - http://creativecommons.org/ licenses/by-nc/3.0/pl/deed.en. 